\title{
Convict ancestry: a neglected aspect of Australian identity
}

\author{
BRUCE TRANTER \\ School of Political Science and International Studies, University of Queensland, \\ St. Lucia, Australia
}

\section{JED DONOGHUE}

School of Sociology and Social Work, University of Tasmania, GPO Box 252-17, Hobart 7001, Australia

\begin{abstract}
Claiming descent from convicts who were sent to Australia during the early period of British settlement is more than just about blood ties, it is also an aspect of national identity for many Australians. Analyses of nationally representative survey data show that younger, left-leaning, working class Australians are most likely to identify as convict descendants, while older, high income, educated, city dwellers are least likely to identify. Our findings also suggest that the 'hated stain' of convict ancestry is senescent, and will diminish with intergenerational replacement. Yet claims to convict descent remain divided along status lines. Interest in convicts and claims of convict heritage may comprise an element of 'popular taste', but as a consequence of this popularity, 'convict chic' is rejected by educated elites. Embraced by 'middle Australia', but shunned by cosmopolitan elites, convict ancestry is a neglected aspect of Australian identity. Whether claims of convict ancestry are 'real' or 'imaginary', the power of foundation myths to provide shared memories is evident in the salience of convict connections in Australia.
\end{abstract}

\section{Introduction}

What counts here are not blood ties, real or alleged, but a spiritual kinship, proclaimed in ideals that are allegedly derived from some ancient exemplars in remote eras. The aim is to recreate the heroic spirit (and the heroes) that animated 'our ancestors' in some past golden age: and descent is traced, not through family pedigrees, but through the persistence of certain kinds of 'virtue' or other distinctive cultural qualities, be it of language, customs, religion, institutions, or more general personal attributes. (Smith 1999: 58)

The celebrations marking the bicentennial of Australian white settlement in 1988 saw a resurgence of interest in Australia's colonial past. These celebrations gave recognition to indigenous Australians, early settlers and, amidst all the flag waving and self-congratulatory back slapping, also brought to the fore those early white Australians who did not arrive by choice, the convicts. The transportation of convicts to Australia, according to Blainey (1966: 149), was in 
essence a form of compulsory, assisted migration, with approximately 168,000 convicts transported before 1868 (Clark 1986: 109). ${ }^{1}$ However, convict heritage was often hidden and considered a 'stain' by later generations. For example, families developed fictional family trees and it was common for 'aging exconvicts couples to be ostracised by their families' (Hay 2000: 3).

Attitudes began to change in the early 1960s and, as Horne (1964: 60) argued, ordinary people who 'could claim an early arrival in the colony as an ancestor - even a convict' gained some slight prestige. During the last decades of the twentieth century, it became more acceptable to acknowledge Australia's convict heritage, rather than conceal it in the manner of previous generations (Fletcher 1992). Re-enactments were the order of the day during the bicentennial celebrations of 1988, including convict trials and floggings, sanitised and romanticised for the consumption of younger Australians (Sayle 1988; Fletcher 1992). ${ }^{2}$ It became increasingly fashionable to uncover a convict ancestor. Early arrivals, especially on the first fleet, were particularly welcome finds (Sayle 1988: 45), with convict ancestry 'one of the most sought-after prizes of genealogical inquiry' (Bennett 1988: 41).

This research is an empirical examination of those who claim convict ancestry. We draw upon questions inserted into the 1999 Australian Constitutional Referendum Survey (Gow et al. 2000) by Ronald Lambert. However, Lambert (2002) used the survey questions for descriptive purposes only. His main aim was to explain why members of genealogical societies embraced their convict ancestry, and consequently his research was based on qualitative interviews. In contrast, we analysed the Referendum Survey questions with multivariate techniques and conceptualised convict ancestry as more than just a genealogical tie. We argue that claims of convict ancestry comprise a neglected aspect of Australian identity, and that convict identifiers are located in terms of their social and attitudinal characteristics, as well as through 'blood lines'.

\section{Myth and memory}

Cultural identities come from somewhere, have histories. But like everything which is historical they undergo constant transformation. Far from being eternally fixed in some essentialised past they are subject to the continuous play of history, culture and power. (Hall 1990: 225)

The resonance of convict identity in Australia is linked to what Hughes calls the 'twin pressures to forget and mythologise' (1987: 158). According to Smith 'genealogy and presumed descent ties, popular mobilisation, vernacular languages, customs and traditions ... are the elements of an ... ethnic conception of the nation' (1991: 12). Smith $(1996,1999)$ identifies three key features of 'myth and memory' necessary for the renewal and resurgence of nationalism: a golden age; an elect ethnic group; and a promised land.

In Australia, the golden age of 'heroes, priests and poets' (Smith 1996) relates to the convicts and free settlers ${ }^{3}$ who carved out British colonies in the 
southern hemisphere. Important foundation myths, from convicts and bushrangers to the goldrush, form the basis of the national history and provide a shared memory. In this instance, the 'emigrant-colonists' and 'chosen people' (Smith 1999: 137), were predominantly English, Irish and Scots, and a very small number of Welsh (Ward 1958: 47), who 'subdued' the indigenous population and kept out 'external enemies' like the Chinese (Phillips 1996: 108). The promised land was a great southern continent, dry and hot, but ripe for European exploration, colonisation and development. In contrast to the early convict arrivals, who could scarcely have regarded the continent as their 'God-given' homeland, contemporary Australians are tied by 'an egalitarian myth' and their 'continued freedom and prosperity' (Smith 1999: 135). To use Horne's (1964) well known phrase, they live in the 'lucky country'. The convict image taps directly into the foundation myths and collective memory of Australia and links people with the chosen (or in this case chained) few who helped found the nation over 200 years ago.

\section{National identity}

Identity is multifaceted, complex and fragmented (Bradley 1996). It is about belonging, and as Weeks claims, " [A]t its most basic it gives you a sense of personal location, the stable core to your individuality. But it is also about your social relationships, your complex involvement with others' (1990:88). Building upon Weeks (1990), Bradley distinguishes personal and social aspects of identity. Personal identity refers to "the construction of the self: our sense of ourselves as unique individuals, how we perceive ourselves and how we think others see us' (1996: 24). By contrast, social identity 'refers to the way that we as individuals locate ourselves within the society in which we live and the way in which we perceive others as locating us' (1996: 24).

Before moving on to describe our study of convict ancestry through the analysis of survey data, there are three dimensions of identity that require brief discussion at this point - passive/active, essentialism/social constructionism and ethnic/civic.

First, Bradley (1996: 25) distinguishes between passive and active identity. ${ }^{4}$ We see convict ancestry as an aspect of identity that is predominantly passive, but one that is also expressed actively, for example, through participation in genealogical societies (Lambert 2002). Public interest in convicts is more broadly expressed through the popularity of convict tourist sites, such as the former Tasmanian penal colony of Port Arthur, and re-enactments of convict experiences at Sydney Cove.

Second, the distinction Calhoun (1994) makes between essentialist and socially constructed identity is central to our research. Social constructionism "challenges at once the ideas that identity is given naturally and the idea that identity is produced purely by acts of individual will' and further, that 'individual persons can have singular, integral, altogether harmonious and 
unproblematic identities' (Calhoun 1994: 13). Constructionists also take issue with 'accounts of collective identities as based on some "essence" or set of core features shared by all members of the collectivity and no others' (Calhoun 1994: 13). We draw upon the distinction between essentialist and socially constructed identity below, as we suspect that many of those who claim convict descent in the survey data are constructing an identity, rather than acknowledging an actual blood line.

Third, as Smith explains, 'ethnicity' has for some 'a "primordial" quality', existing 'in nature, outside time' (1991: 20). This may be contrasted with 'situational' conceptions of ethnicity that are related to 'attitudes, perceptions and sentiments that are necessarily fleeting and mutable, varying with the particular situation of the subject'. This allows ethnicity to be used " "instrumentally" to further individual or collective interests' (Smith 1991: 20). The contrast between 'ethnic' conceptions of nation that emphasise 'community of birth and native culture' and 'civic' forms based upon ' $[\mathrm{H}]$ istoric territory, legal-political community, and legal-political equality of members, and common civic culture and ideology' (Smith 1991: 11) is an important distinction in the context of our research. Our study may be situated within the body of recent articles whose authors have sought to distinguish empirically these aspects of national identity in Australia (e.g. Pakulski and Tranter 2000a, 2000b; Jones 1997; Phillips 1996, 2000), and in cross-national comparative research (e.g. Pakulski and Tranter 2002; Jones and Smith 2001).

Pakulski and Tranter (2000b), for example, mapped the social correlates of what they termed 'ethno-national' and 'civic' identity types. Their 'civic' identity was characterised by 'the centrality of voluntary ties, interdependence and shared commitments to the core institutions of a society', while 'ethnonationals' stressed 'the importance of more "primordial ties" acquired by birth and long residence, the ties that bind us to the ethnically defined and culturally circumscribed nation' (Pakulski and Tranter 2000b: 218). ${ }^{5}$ They found that the tertiary educated, members of the 'baby boom' generation, and middle-class identifiers were more likely to associate with a 'civic' form of identity. Their 'ethno-nationalists' tended to be born before World War II and were less educated, but more religious (particularly of Anglican denomination) and more likely to be married or in de facto relationships (2000b: 213). In an earlier but related work, Jones (1997: 291) distinguished 'Australian nativism' from 'civic culture', claiming that the former identity type 'looks backward to a vision of Australia that is fading', while 'civic culture, a more abstract and open concept, looks forward to a future already in the making' ${ }^{6}$

Our study differs from previous Australian empirical research on identity in at least one important way. Earlier studies (e.g. Pakulski and Tranter 2000b; Jones 1997; Phillips 1996) based their findings upon attitudinal survey questions, questions that were constructed by researchers in order to tap various aspects of national identity. In contrast, our research relates to an actual historical event - the transportation of convicts to former British colonies. By considering the characteristics of those who claim to have had 
convict ancestors, we attempt to examine a more grounded identity claim, but, as we shall see, a form of identity that is not necessarily essentialist.

Claims to convict ancestry may be ethnicity claims, because as Lambert (2002: 119) notes, descendants of convicts comprise 'a minority within a multicultural society'.

Respondents also advanced a multicultural argument that positioned them as convictdescendants within Australia's evolving ethnic and racial mosaic. In claiming convictdescendant identities, they asserted both their families' temporal primacy and their contributions to the foundation of modern Australia, which they feared may be otherwise eclipsed and forgotten. (Lambert 2002: 119)

In that sense, claims of convict ancestry contain essentialist elements, as some contemporary Australians are able to trace their bloodlines directly to the early transportees. However, to a certain extent we view claims of ancestry in the survey data as social constructions and draw on the results of our analyses to demonstrate this point. If identity is linked to social relationships (Weeks 1990), and stems 'from the various sets of lived relationships in which individuals are engaged' (Bradley 1996: 24), convict ancestry should be associated with certain social and attitudinal correlates in the survey data.

However, before discussing our empirical analyses, it is necessary to outline our expectations. Although we suspect that convict identity is a social construction for some Australians, we view identity as a complex phenomenon that comprises both essentialist and socially constructed elements, and expect to find evidence of both in the survey data. Some essentialist aspects of identity are difficult to capture with survey data, but should be apparent in state-based differences in claims to convict ancestry, because of the uneven dispersion of convicts who were transported to the former colonies.

According to Robson (1965: 4), a total of 80,440 convicts were transported to New South Wales, and 67,140 convicts to Tasmania, but only 15,441 convicts to the remaining colonies. ${ }^{7}$ As a settler state, South Australia received no transportees, while Tasmania had the largest proportion relative to its population size. By the mid-nineteenth century, 34.4 per cent of the Tasmanian population were, or had been, convicts (Hughes 1987: 162). Tasmanians are therefore most likely to be descended from convicts - even given subsequent interstate migration - while South Australians should have the lowest proportion of convict descendants and claimants.

Further, those whose parents and ancestors were born in Australia should be most likely to claim convict lineage, as they have a greater chance of being blood relatives. ${ }^{8}$ In addition, older people, at least those whose ancestors were born in Australia, should be more likely than their younger counterparts to be descended from convicts, due to the significant period of immigration following World War II. ${ }^{9}$

What would we expect to find following a socially constructed notion of convict identity? We search for evidence of the social construction of convict identity claims by considering several socio-demographic indicators. Failure to 
find evidence of variation in the social background of those claiming convict descent would count heavily against the social construction thesis. We expect socially constructed aspects of convict ancestry to be linked in a certain way to elements of social location, such as social class, education and income, because such indicators are in turn linked to different patterns of cultural consumption and taste (Gans 1974; Bourdieu 1984).

As Turner contends, '[W]hile status is about political entitlement and legal location within civil society, status also involves, and to a certain extent is style. The location of a group within a social system is expressed by their taste, which is as it were the practical aspect of lifestyle' (1988: 67). ${ }^{10}$ Bourdieu identified 'three zones of taste ... [that] ... roughly correspond to educational levels and social classes' (1984: 16). He linked 'legitimate', 'middle-brow' and 'popular' taste cultures with the upper, middle and working classes, respectively. We expect that claims to convict ancestry are, to an extent, status and lifestyle based, with consumers of what Gans (1974: 70) refers to as 'high culture', and Bourdieu (1984: 16) calls 'legitimate' taste, ${ }^{11}$ least likely to claim convict relatives. ${ }^{12}$ Accordingly, we expect that highly educated and higher income Australians will be less likely to claim convict ancestry, while the working class should be more likely to claim.

Drawing upon the work of Jones (1997) and Pakulski and Tranter (2000b), we also use attitudinal survey questions to explore the ethnic/civic dimension of convict identity. If there is an ethnic basis to claims of convict ancestry, as Lambert's (2002) research indicates, we expect Pakulski and Tranter's (2000b) 'ethno-nationalists' will be more likely to claim convict descent than their 'civic' form. If we are correct in expecting a higher incidence of convict identifiers among 'ethno-nationalists' than 'civic' identity types, we have further cause to anticipate a corresponding class cleavage to emerge in relation to convict identity claims. Pakulski and Tranter (2000b) found the working class to be aligned with 'ethno-nationalists', and the middle class more closely associated with a 'civic' form of Australian identity. We therefore expect that class location should play a part in convict identity claims, with the working class more likely than other classes to claim convict ancestors.

Finally, we include home ownership as another proxy measure for status. Again we expect that higher status Australians - in this case outright home owners - should be less likely than home buyers, or those living in rental accommodation, to claim convict ancestry. We now turn to the empirical analyses, following a short digression in order to describe the data and methods employed in our analyses.

\section{Data and methods}

We analysed data from the 1999 Constitutional Referendum Study (Gow et al. 2000) obtained from the Social Sciences Data Archive, Australian National University $(n=3431)$. These data were obtained by self-completed 
questionnaires administered by mail between 5 November 1999 and 2 March 2000. Respondents were identified through a probability sample (disproportionate stratified systematic sample) drawn from the Australian electoral roll. Larger states were proportionately under-represented, and smaller states overrepresented, in the full sample, in order to collect adequate numbers of respondents to enable comparative analyses at state level. A weighting variable provided with these data corrects the sample estimates to be representative of the Australian population (weighted $n=2311$ ).

Analyses were conducted with SAS (version 8). A multiple regression technique was used to estimate population parameters for the convict ancestry question presented in Table 1, based on the values of our independent variables. We combined the 'Yes, I am' with the 'I may be' categories and contrasted these with 'No, I am not' for the purpose of the regression analyses. ${ }^{13}$ 'Don't know' responses were excluded from our analyses. As the resulting dependent variable is dichotomous, logistic regression was employed as an appropriate method (see Long 1997; Agresti 1996).

Anderson has pointed out that nations are 'imagined, because the members of even the smallest nation will never know most of their fellow-members, meet them, or even hear of them, yet in the minds of each lives the image of their communion' (1991: 6). We realise that some, or indeed even most, survey respondents may not know for certain whether they are descended from convicts. This is a potential problem in survey research, when respondents do not have sufficient knowledge to answer a question accurately (de Vaus 2002: 98). However, in this instance we have turned a possible problem to our advantage, as we expect that the convicts survey question also captures those attracted to the myth of convict ancestry, and as such, we also capture these 'imagined descendants'. Smith's argument is also pertinent here: 'it is notoriously difficult to disentangle the elements of genuine shared memory from those of exaggeration, idealization and heroisation which we associate with myth and legend, since there is usually more than a kernel of truth in the latter' (1996: 583).

Table 1. 'To the best of your knowledge, are you descended from one or more of the convicts who were sent to Australia during the early period of British settlement in this country?' (per cent)

\begin{tabular}{lll}
\hline \hline & \% unweighted & \% weighted \\
\hline Yes, I am & 12.6 & 11.3 \\
I may be & 11.6 & 11.3 \\
No, I am not & 58.4 & 59.9 \\
I really don't know & 17.4 & 17.5 \\
$n$ & $(3431)$ & $(2311)$ \\
\hline \hline
\end{tabular}

Source: 1999 Australian Constitutional Referendum Survey. 
Several independent variables are introduced to the regression equation in blocs. Hewitt claims that 'the fundamental reference of identity is social location' (1989: 127 in Calhoun 1994: 14). To that end, we consider the impact of social location by regressing the dependent variable on age, sex, tertiary education, family income categories, marital status and religious denomination. Place and residence are then introduced to the equation. These variables include Australian states (Tasmania and South Australia compared with other states), ${ }^{14}$ residence in a large city (over 100,000 people) and home owners. We contrast the self-assessed working-class category with other class categories, ${ }^{15}$ and include an ideology scale (left to right) derived from the question 'In politics, people sometimes talk about the "left" and the "right". Where would you place yourself on a scale ranging from 0 to 10 , where 0 means the left and 10 means the right?'

Principal components analyses were employed to examine the underlying structure of several Likert-type attitudinal questions, and to develop four additive scales. Some important aspects of Australian identity identified by Pakulski and Tranter (2000b) and Jones (1997), were tapped with scales measuring pride in Australian national achievements $($ Alpha $=0.71)$ and political achievements $($ Alpha $=0.72),{ }^{16}$ general approval of immigrants $($ Alpha $=0.72)$ and approval of Aboriginals $($ Alpha $=0.87) .{ }^{17}$

Other aspects of national identity that relate directly to Jones' (1997) 'nativist' and Pakulski's and Tranter's (2000b) 'ethno-nationalist' identity types, such as having been born in Australia, and having lived in the country for a long period of time, were measured with dummy variables (very important+fairly important versus not very important+not at all impor$\operatorname{tant).}{ }^{18}$ In the final model, a parental country of birth scale was included as a control variable. ${ }^{19}$

Odds ratios are presented to facilitate the interpretation of the logistic regression estimates. For example, the odds ratio of 1.64 for Anglican denomination in Table 3 is interpretable as follows: Anglicans are approximately 1.6 times more likely than Catholics, or other religious denominations (i.e. the reference category), to claim convict descent, as opposed to not claiming convict descent. Odds ratios less than unity indicate a negative association. ${ }^{20}$

With the exception of age (measured in its natural metric), the ideology scale and the attitudinal scales (rescored to range between 0 and 1), all independent variables are dummy variables and therefore should be interpreted in comparison to their reference categories. Missing cases for the independent variables were replaced with their mean scores for scale variables.

\section{Analyses}

Cross tabulation analyses (Table 2) show it is highly likely that all of the social location variables are related to convict descent in the Australian population, 
Table 2. Convict identity and social location (per cent)

\begin{tabular}{|c|c|c|c|}
\hline Descended from convicts? & Am or may be & Not & $p$ \\
\hline Men & 26.4 & 73.6 & \\
\hline Women & 28.3 & 71.7 & .193 \\
\hline Born $<=1945$ & 19.2 & 80.8 & \\
\hline Born 1946-59 & 25.2 & 74.8 & \\
\hline Born $1960+$ & 35.4 & 64.6 & .000 \\
\hline Postgraduate degree & 18.7 & 81.3 & \\
\hline Bachelor degree & 22.3 & 77.7 & \\
\hline Diploma & 21.5 & 78.5 & \\
\hline Associate diploma & 30.5 & 69.5 & \\
\hline Trade qualification & 27.1 & 72.9 & \\
\hline Non-trade qualification & 29.5 & 70.5 & \\
\hline No qualification & 31.1 & 68.9 & .031 \\
\hline Family income $\$ 0-\$ 20 \mathrm{~K}$ & 26.1 & 73.9 & \\
\hline Family income $\$ 20-\$ 40 \mathrm{~K}$ & 32.1 & 67.9 & \\
\hline Family income $\$ 40-\$ 60 \mathrm{~K}$ & 32.2 & 67.8 & \\
\hline Family income $\$ 60 \mathrm{~K}$ plus & 24.4 & 75.6 & .016 \\
\hline Managers & 22.2 & 77.8 & \\
\hline Professionals & 22.3 & 77.7 & \\
\hline Associate professionals & 19.9 & 80.1 & \\
\hline Tradespeople & 29.9 & 70.1 & \\
\hline Advanced clerical & 31.0 & 69.0 & \\
\hline Intermediate clerical & 29.8 & 70.2 & \\
\hline Plant operators/drivers & 31.9 & 68.1 & \\
\hline Elementary sales and service & 42.4 & 57.6 & \\
\hline Labourers & 19.1 & 80.9 & .000 \\
\hline Roman Catholic & 23.4 & 76.6 & \\
\hline Anglican/Church of England & 32.6 & 67.4 & \\
\hline Uniting/Methodist & 33.9 & 66.1 & \\
\hline Orthodox Church & 11.3 & 88.7 & \\
\hline Presbyterian & 25.3 & 74.7 & \\
\hline Other & 22.9 & 77.1 & \\
\hline None & 29.7 & 70.3 & .000 \\
\hline Rural village & 29.0 & 71.0 & \\
\hline Small country town & 33.3 & 66.7 & \\
\hline Larger country town & 40.8 & 59.2 & \\
\hline Large town & 31.7 & 68.3 & \\
\hline Major city & 22.4 & 77.6 & .000 \\
\hline Own a house outright & 20.4 & 79.6 & \\
\hline Mortgage & 31.5 & 68.5 & \\
\hline Rent private & 34.4 & 65.6 & \\
\hline Rent public & 39.0 & 61.0 & \\
\hline Other & 31.6 & 68.4 & .000 \\
\hline Never married & 35.4 & 64.6 & \\
\hline Currently married/de facto & 24.8 & 75.2 & \\
\hline Widow & 20.4 & 79.6 & \\
\hline
\end{tabular}


Table 2. (Continued)

\begin{tabular}{lccc}
\hline \hline Descended from convicts? & Am or may be & Not & $p$ \\
\hline Divorced/separated & 34.5 & 65.2 & .000 \\
New South Wales & 30.5 & 69.5 & \\
Victoria & 23.9 & 76.1 & \\
Queensland & 26.3 & 73.7 & \\
South Australia & 18.5 & 81.5 & \\
West Australia & 26.7 & 73.3 & \\
Tasmania & 48.9 & 51.1 & .000 \\
Self assessed class & & & \\
Upper & 22.4 & 77.6 & \\
Middle & 24.7 & 75.3 & \\
Working & 31.5 & 68.5 & \\
None & 25.4 & 74.6 & .017 \\
\hline
\end{tabular}

Notes: $p$ is the probability value based on chi-squared tests for statistical independence. Source: 1999 Australian Constitutional Referendum Survey.

with the exception of gender. Younger Australians are more likely to identify with convict ancestors, with the impact of age declining in a linear fashion. Reasonably large percentage differences are also apparent for religious denomination, residence and home ownership. Most striking, however, are the state-based differences. Almost half of all Tasmanians (48.9 per cent) say that they are or may be descended from convicts, compared with only 19 per cent of South Australians, while approximately 31 per cent of those living in the first colony - New South Wales - say that they are or may be of convict descent.

To estimate the net effect of each independent variable on convict ancestry, we use multiple logistic regression analyses. Each odds ratio presented in Table 3 'controls' for the potentially confounding impact of all other independent variables. In addition to the social location variables shown in Table 2, we also add attitudinal and parental birthplace measures as predictors. ${ }^{21}$

There is certainly evidence in these data that claims of convict descent are socially constructed, but in some instances not entirely according to our expectations. Contrary to our predictions, and against what would constitute evidence of a blood ties explanation, younger rather than older Australians are likely to claim convict descent. However, we did detect statistically significant differences based upon education, income, marital status and religious denomination, largely in accordance with our expectations (Model 1). Tertiary graduates are less likely than those without a degree to claim descent, signaling our expected status effect, while higher income earners (i.e. based on combined family income) are also less likely to say that they are descended from convicts. Being married or in a de facto relationship compared with other marital statuses also has a negative effect, while Anglicans and Methodists are more 
likely to claim convict ancestry than other religious denominations. Gender has no statistically significant impact, although there is no demographic reason that it should.

Tasmanians are about twice as likely as people living in other states to claim convict ancestry, not surprisingly, given the sheer number of convicts sent to the smallest state (Hughes 1987: 162). Also expected is the South Australian result. Residents from the 'settler state' of South Australia where convicts were not transported, were only about half as likely to claim convict ancestry as those from the remaining states. While predictable, however, if we did not find such results, there would be cause for concern over the validity of these data.

Living in large cities reduces the likelihood of identifying with convict ancestors. On the face of it, this could be due to the large numbers of migrants attracted to large cities for employment. However, this effect remains after we control for parental birthplace. Owning one's home outright reduces the likelihood of claiming convict heritage over the reference group (mortgagees and renters). Self-placement on the left of the ideological spectrum increases claims of convict ancestry, while the working class are more likely than the middle class to claim descent from early forced settlers. An interest in family history is also associated positively with claiming convict ancestry.

The attitudinal independent variables introduced in Model 4 also produce some notable results. While pride in Australian national achievements and the Aboriginal scale have no statistically significant impact at the .05 level, the other three attitudinal variables are all highly significant predictors of convict descent. Pride in Australian political achievements and approval of migrants are both negatively correlated with convict descent, while those who agree that to be 'truly Australian' it is necessary to have been born in Australia, are almost twice as likely to claim convict ancestry (O.R. 1.70). These attitudinal results suggest a link between convict identity and the 'ethno-nationalist' identity type referred to by Pakulski and Tranter (2000b). That is, the results suggest 'ethnonationalists' are more likely than 'civics' to claim convict identity.

Parental birthplace was chosen over respondent birthplace as a more valid measure of controlling for blood ties to convict ancestors. Having both parents born in Australia increases the likelihood of convict identity by almost seven times, compared to having both parents born overseas (Model 6). While on the face of it, this result is not surprising, the fact that 11 per cent of convict claimants have both parents born overseas is intriguing. It seems unlikely that such a relatively large proportion of respondents are actually descended from convicts, and we interpret this as further evidence of the social construction of convict ancestry. We also include parental country of birth as an important control variable in these analyses. This not only adjusts for post-war immigration, but also controls for the large migrant communities in major cities. However, even holding parental birthplace constant, age, state, city residence and marital status, as well as the migrant scale and the born in Australia measure, are all important indicators of convict ancestry in Model 8. 


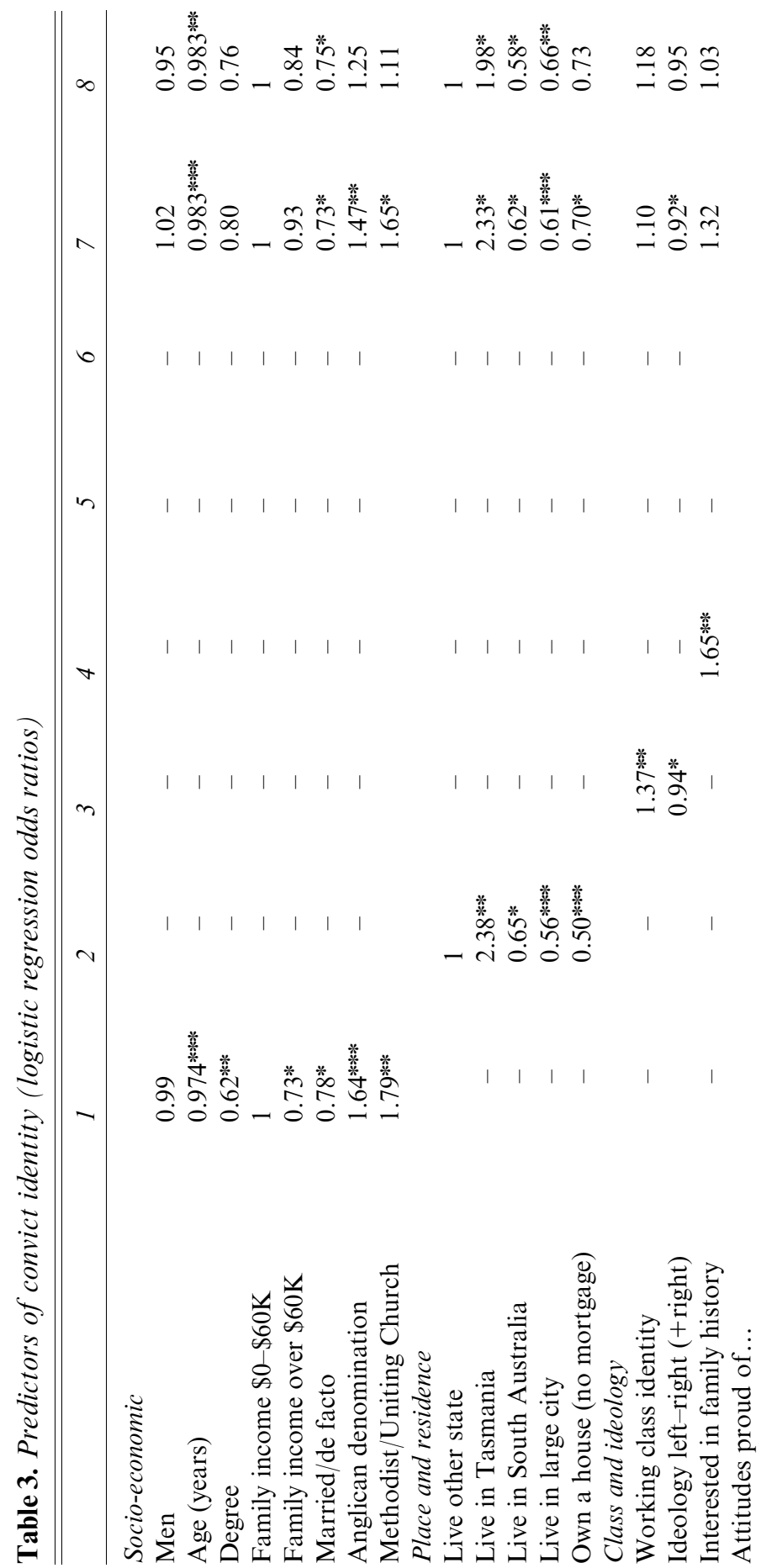




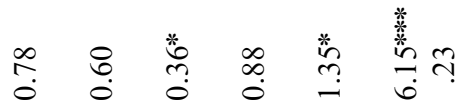

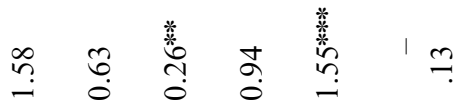

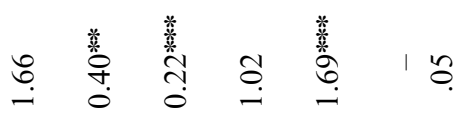

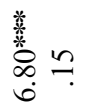

$$
\begin{aligned}
& 1 \quad 1 \quad 11 \%
\end{aligned}
$$

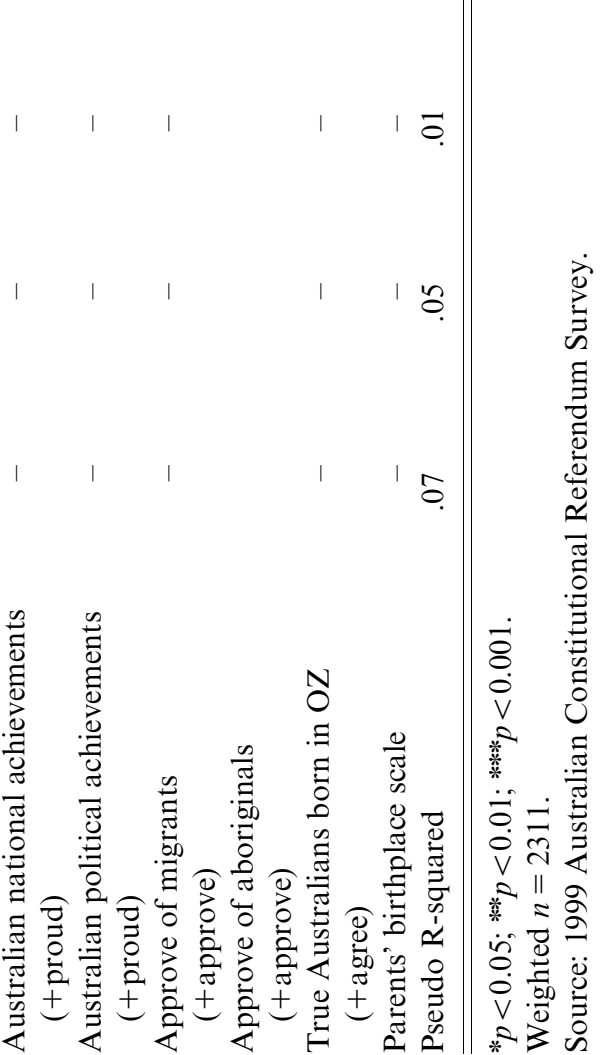


While there are sound demographic reasons why 'older' Australians are more likely to be descended from convict stock - that is their blood lines should be stronger given the level of post-war immigration - we found quite the opposite relationship between age and convict identity. Older people were less likely to claim convict ancestors in these data. This can perhaps be interpreted as evidence of the 'hated stain', a rejection of the convict past that remains stronger among older Australians. In support of such a claim, the survey data show that younger people are more interested in searching their family tree. ${ }^{22}$ However, it is notable that in his study of genealogical societies, Lambert (2002: 114) found that those most likely to search for convict ancestors tended to be older. ${ }^{23}$ While these disparate results were obtained from very different methodological approaches and from very different data sources, ${ }^{24}$ it may be the case that while younger people are more likely to be 'interested' in their family history, older people are more likely to act upon such interests.

In order to explore the relationship between age and convict identity more closely, we conducted multiple logistic regression analyses separately for each of the states (Table 4). Controlling for sex, education, location and interest in family history, we found that age - or as we model it here, generation - was a highly significant predictor of convict identity in all states. Those born before the end of World War II were least likely to claim convict ancestry, and in three of the six states (Victoria, Queensland and Tasmania), members of the 'baby boom' generation were also less likely than 'generation Xers' to claim convict descent. Again these are counterintuitive findings. We had expected age to be an important variable, but expected the relationship between convict descent and age to be positive rather than negative. These findings support our claim that the phenomenon we are measuring is, to an extent, socially constructed identity. While the generational effects are evidence of the persistence of the 'hated stain' among older Australians, they also suggest that it is senescent, and should diminish with intergenerational replacement.

We should sound a note of caution given the context in which these data were collected - the 1999 Australian Constitutional Referendum. The publicity surrounding the referendum and the campaign prelude may have had an impact on convict descent claims. Perhaps some of the generational effects were influenced by greater interest in a republic among younger Australians, leading to a heightened interest in Australian history and subsequent identification with convicts. The ACRS included questions relating to these issues. While there was a positive and significant bivariate relationship between interest in family history and claims of convict ancestry (Table 3, Model 5), this relationship was quite weak, and washed out in the full regression model. Further, as shown in Table 4, interest in family history was a statistically significant predictor of convict identity in New South Wales only. We also attempted to examine as best we could the association between age and interest in the republic. ${ }^{25}$ In bivariate logistic regression analyses we found that age was not associated with interest in the referendum campaign (OR $1.00 ; p=.4388$ ), nor did interest in the referendum increase the likelihood of claiming convict 


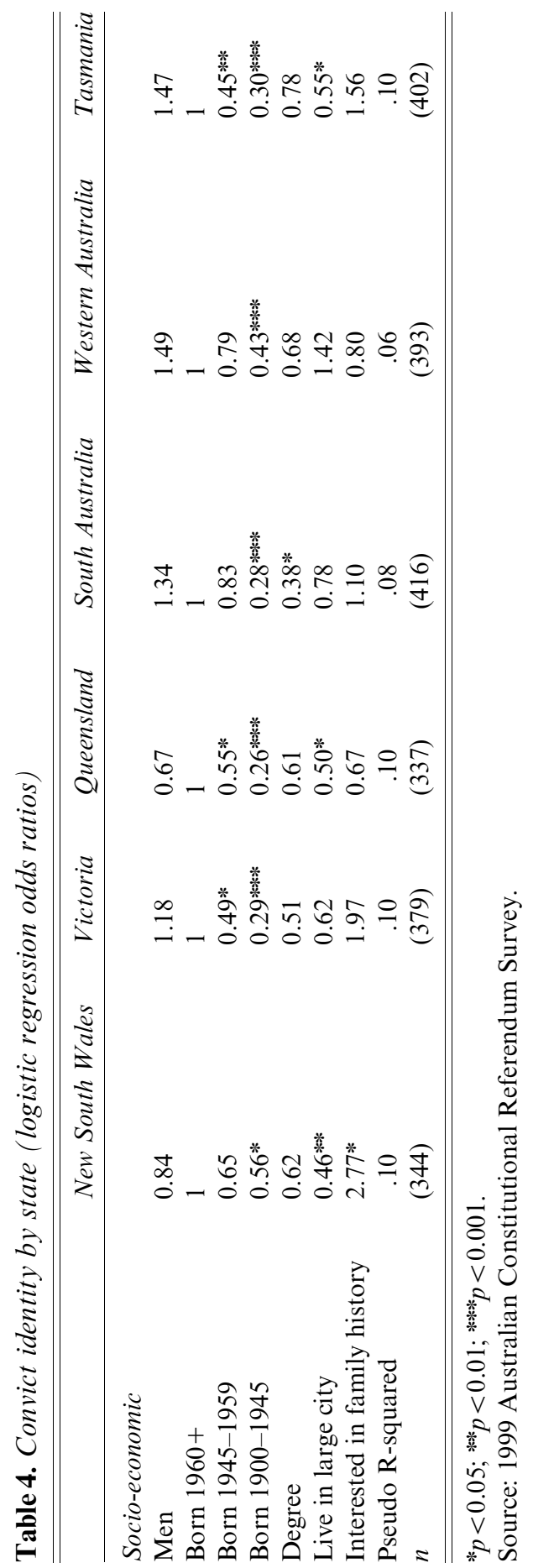


ancestry (OR $0.94 ; p=.6027$ ). These results indicate that age effects on the likelihood of claiming convict descent were unlikely to be due to age-related differences in historical interest, brought about by the 1999 Referendum. Once again, these age findings seem to indicate an abhorrence of the 'hated stain' of convict ancestry among older Australians, even when we hold social status constant.

\section{Discussion}

The transformation of convict identity into a positive foundation image has been paralleled by the reclamation of indigenous identity in Australia. For example, in My Place, Sally Morgan (1987) related the discovery of her Aboriginality that had been hidden due to family shame and community prejudice. ${ }^{26}$ Macintyre argued that '[A]boriginality was becoming more fluid, less a product of biology than a cultural and emotional affinity' (1999: 261). However, the increasingly proud display of Aboriginal identity ${ }^{27}$ has also aroused community suspicion and challenges based on bloodlines and authenticity. Macintyre noted that 'Aboriginal communities were understandably suspicious of the change; they insisted on both descent and connection' (1999: 161). ${ }^{28}$

If there has indeed been an increase in claims of convict descent over recent decades, this too, may be analogous to the case of Aboriginal identity. Tyler argues that Aboriginal 'identity is increasingly defined in terms of an individuated act of self-identification (e.g. on a census form, or admission to a penal institution) rather than by either biological descent or collective ritual' (1999: 213). He describes how 'census counts of the Aboriginal and Islander population increased by 55\% between 1986 and 1996, and 33\% between 1991 and 1996, a phenomenon which has challenged many of the assumptions of conventional demographic analysis' (Tyler 1999: 213). Tyler suggests that the dramatic increases in "the Aboriginal population of Australia and other "settler" societies...can usually be attributed to more efficient methods of enumeration and to increasing rates of out-marriage' (1999: 213). However, Smith's (1991: 20) notion of the 'instrumental' quality of ethnicity is also relevant here, as claims to Aboriginality may also be sought in order to obtain government assistance in relation to the provision of education, housing or even in claims to ancestral landrights.

There are also parallels in the growth of ethnic and racial identities in the United States. Hout and Goldstein argued for the importance of the 'subjective component of ethnic identity' as a factor that could help explain increases in the proportion of Americans claiming Irish or German descent (1994: 79). In research that employed both sociological and demographic methods, they found 'the social increase of the Irish and German populations in America has far outstripped their natural increase' (1994: 79) ${ }^{29}$ Similarly, as pointed out by Tyler (1999: 213), Nagel (1995) and Snipp (1992) demonstrated impressive 
increases in the proportion of US citizens who identified as American Indians, while Siggner (1993) reported similar increases among Canadian Aboriginals.

Hughes (1987) and Warhurst (1993) provide clues that help to explain attitudinal differences toward convict ancestry in Australia. Hughes (1987: 158-81) identifies 'class divisions between guards and prisoners' reinforced by cultural differences between English and Irish convicts and settlers that still resonate today. A notable class divide was also apparent in the membership and support bases of the major political parties. The Australian Labor party has, according to Warhurst, 'been influenced by a strong residue of anti-British feeling stemming from the predominance of Catholics of Irish-Australian decent' (1993: 106). In contrast, the Liberal party has traditionally been led by (Anglican) leaders who are pro-British and emotionally attached to the monarchy and tradition' (Warhurst 1993: 104). In fact, there was a tendency for those claiming convict ancestry to have voted Labor at the 1998 Federal Election, although this relationship disappeared when we controlled for social class. ${ }^{30}$

Our analyses suggest that there are certain groups - better conceptualised as status categories - whose members are more or less likely to make convict identity claims. Controlling for other factors, older, highly educated, higher income, large city dwellers are less likely to claim a convict ancestor, particularly if they happen to own their own home. On the other hand, younger, less educated, left-leaning and working class Australians are most likely to say they are descended from convicts. The class, education and income effects suggest that lower status Australians - perhaps those with relatively heavy financial responsibilities - are most likely to identify with convicts. In a search for identity, they adopt a more 'active' identification (Bradley 1996: 25) as they are more likely to claim their (alleged) convict ancestry.

Claiming convict identity is less attractive to high status, highly educated, large city dwelling Australians who may appreciate that 'eight out of ten convicts were thieves' (Hughes 1987: 159). In contrast to the romantic view of the transported as put upon, urban poor and agrarian itinerants, according to Hughes 'far from being first offenders...', many '...carried previous convictions' (1987: 158-9), while Robson pointed out that 'certainly one-half, and probably two-thirds, had formerly been punished, usually for forms of theft' (1965: 9).

Our expectation that convict identity would be rejected by consumers of 'high culture' (Gans 1974) or as a form of 'legitimate' taste (Bourdieu 1984) is also likely to hold. The tertiary education, higher income and home ownership findings, while again not direct measures of cultural consumption, support such claims. Similarly, as upper and middle class location is associated with the consumption of 'high culture' in Australia (see Bennett et al. 1999), our findings relating to the subjective working-class background of convict identifiers suggest that convict identity may be linked to cultural consumption 
patterns in a particular way (i.e. convict identity is in the realm of 'popular' culture). Nevertheless, further research is required to verify this potential link between cultural consumption and convict identity.

The foundation images embodied in claims to convict ancestry, may help explain why traditional identities remain strong in many developed societies 'despite globalisation, mass migration and cultural pluralism' (Jones and Smith 2001: 45). Our research suggests that claims to convict descent are partly associated with an essentialist form of national identity discussed in earlier Australian research. Our socio-demographic findings relating to non-tertiary education, the working-class location of convict identifiers and the negative association between convict identifiers and attitudes toward migrants, ${ }^{31}$ indicates proximity to an 'Australian nativist' (Jones 1997) or 'ethnonationalist' identity type (Pakulski and Tranter 2000b). A more direct indication was obtained through our measure of 'ethno-nationalist'/"nativist' identity included in the regression models. We found that those for whom being born in Australia was an important component of being 'truly Australian' were more likely to claim convict ancestry. Convict identifiers are therefore aligned with the primordial, 'ethno-national' identity type suggested by Pakulski and Tranter (2000b).

Convict identifiers tend to be lower or middle ranking on a range of social indicators, such as education, class, housing tenure and income, even when age is held constant. One interpretation of these findings is that claims of convict ancestry are divided on the basis of achieved status. Our findings are consistent with Lambert's (2002: 119) qualitative research on genealogical societies, where convict descendants asserted that they formed 'a minority within a multicultural society'. Claiming to have convict ancestors may be a strategy adopted by some 'white' Australians in order to make an ethnic identity claim of their own. Seen in this light, such claims from certain groups within the mythical 'middle Australia', constitute a claim to a form of 'white Australianness', that is neither indigenous, nor an 'ethnic' identity associated with post World War II immigrants. ${ }^{32}$

However, beyond being a claim to ethnic minority group membership, convict identity is not pursued as an 'instrumental' ethnicity claim in order to further 'individual or collective interests' (Smith 1991: 20). Indeed, higher status Australians shy away from their convict past. Returning to Weeks' (1990: 88) assertion that identity is a 'sense of personal location', Australians who have 'achieved' relatively high status, for example, through higher education or employment in professional occupations, appear less inclined to search for a sense of identity in the past.

The propensity to claim convict identity among those who live in large cities is lower, again pointing to a rejection of convict identity among cosmopolitan Australians. ${ }^{33}$ There is a parallel here with the so-called 'Great Divide' between the educated, professional, cosmopolitan 'Australian intelligentsia' and mainstream 'parochials' (Betts 1999: 3). While higher status Australians are willing to embrace multiculturalism and approve of immigration - an 
indication of their alignment with 'civic' as opposed to 'ethno-nationalist' identity (Pakulski and Tranter 2000b) - our results suggest that they are far less inclined to claim convict heritage. If interest in convicts, and claims to convict heritage comprise an element of 'popular taste' (Bourdieu 1984), perhaps 'convict chic' has been rejected by educated elites as a consequence. ${ }^{34}$

Claims of convict heritage are a neglected aspect of Australian identity. As convict sites have been re-invigorated, they have provided images for tourist consumption (Bennett 1988: 41), and as convicts have developed into a 'popular Australian stereotype' (Hughes 1987: 158), they have captured the imagination of 'middle Australia'. Whether these comprise the claims of 'real' or 'imagined' descendants, the power of foundation myths to provide shared memories is evident in the increased salience of 'convict connections' in Australia.

\section{Notes}

1 We note that there are discrepancies between sources regarding the numbers of convicts sent to Australian colonies. However, as Robson suggests 'no evidence has been found that a careful official calculation was made of all convicts ever sent to Australia' (1965: 4).

2 Bennett notes that ' $[\mathrm{T}]$ wenty to thirty years ago, most penal institutions from the convict period were either disused or dedicated to other government functions. Since then, the number of such institutions - as well as late nineteenth century prisons - which have been converted into museums is truly remarkable. Port Arthur, Hyde Park Barracks, Old Melbourne Gaol and Old Dubbo Gaol, are among the most obvious examples' (1988: 40).

3 Pusey suggests that 'early settlers were for the most part the victims of the industrial revolution and the ugliest period of militant British capitalism' (1988: 25). According to McQueen, writing on early settlers, 'Late in December 1848, the radical newspaper The People's Advocate gave an accurate appraisal of the migrant mentality: "the mechanic who emigrates to this colony has the same object in view as the capitalist. Ask any one what he came to the colony for, and his answer will be: to better his condition"” (1986: 122-3).

4 Bradley also refers to politicised identity, although we have found no evidence that convict identity is in any way politicised.

5 'Ethno-national' identity involves strong social attachments to the Australian 'nation' seen as 'a specific and shared culture, traditions and customs', while 'civic' identity is characterised by attachment to Australian 'society' as 'a voluntary association of people sharing major social institutions and commitments' (Pakulski and Tranter 2000b: 209). They also consider a third 'denizen' form of identity signified by a weak social attachment (Pakulski and Tranter 2000b: 209). This form is less relevant to our discussion.

6 Jones also argued that 'behavioural aspects of identity, like citizenship and language, form a bridge between the two' (1997: 29).

7 In terms of gender, the vast majority of convicts were male, with only 24,960 women transported (Robson 1965: 9).

8 Nevertheless, some 11 per cent of respondents who indicated that they were, or may be, descended from convicts had both parents born overseas, while 12 per cent had one parent born in a country other than Australia. We therefore control statistically for this relationship in the regression models with a scale variable measuring parental place of birth.

9 According to Australian Census data for 2000, 24 per cent of Australians were born overseas, with 6.3 per cent born in the United Kingdom or Ireland, and 12.5 per cent in Europe, including former Soviet countries (Australian Bureau of Statistics 2002). 
10 In a later work, Bourdieu acknowledged this link when he noted: 'social space, and the differences that "spontaneously" emerge within it, tend to function symbolically as a space of lifestyles or as a set of Stände, of groups characterised by different life-styles' (1991: 237).

11 According to Erickson, Bourdieu 'argues that class and culture are both vertically ranked in mutually reinforcing ways. The culture of the highest classes becomes the most distinguished culture, apparently because it is innately superior but really because it is the culture of those who rule' (1996: 217). In Australia, Bennett et al. (1999: 102-3) found consumption of 'high culture' was greater among the highly educated and those employed in managerial and professional occupations.

12 What comprise 'classes' for Bourdieu resemble status groups for Turner, who maintained: '[W]hile status is about political entitlement and legal location within civil society, status also involves, and to a certain extent is style' (1988: 66-7). While there are no direct measures of cultural consumption in the ACRS data, we examine aspects of social location that are known correlates of consumption based lifestyle in Australia.

13 While this approach may seem to conflate two categories that are quite different (i.e. I am and I may be), analyses of these data operationalising a three-category dependent variable (I am, I may be, I'm not descended from convicts) with multinomial logistic regression produced very similar results. For reasons of parsimony, we elected to analyse the dichotomous dependent variable.

14 The Australian Capital Territory and the Northern Territory were omitted from the analyses due to the very small number of respondents (unweighted: New South Wales $=507$; Victoria $=557$; Queensland $=517$; South Australia $=607$; Western Australia $=548$; Tasmania $=588 ;$ ACT $=57$; $\mathrm{NT}=22$ ).

15 As shown in Table 2, the major class differences in claims of convict ancestry occurs between the working class and the three remaining classes (i.e. upper, middle, none). We therefore contrast the working class and other classes in the regression models.

16 These scales are derived from the following question: 'How proud are you of Australian ... in each of the following?', followed by descriptive terms. The achievements scale included the items: Australian science; history; armed forces; sports and art. The political achievements scale included the items Australian democracy, influence and economics. Response categories were very proud, fairly proud, not very proud, not proud at all.

17 These scales were constructed by adding responses to the question: 'The statements below indicate some of the changes that have been happening in Australia over the years. For each one, please say whether you think the changes have gone too far, not gone far enough, or is it about right.' The Migrants scale combines the following items: equal opportunities for migrants; number of migrants allowed into Australia; building closer links with Asia. The Aboriginal scale added the items: Aboriginal land rights; Government help for Aboriginals. The response categories for these items were: gone much too far; gone too far; about right; not gone far enough; not gone nearly far enough.

18 This dummy variable was derived from the following question: 'Some people say the following things are important for being truly Australian. Others say they are not important. How important do you think each thing is? - Being born in Australia'. After initial analyses, the 'lived in Australia a long time' measure was excluded.

19 Respondents with both parents born in Australia were scored 1, those with one parent born elsewhere were scored 0.5 , and those with both born elsewhere scored 0 .

20 OR less than 1 for dummy variables indicate an estimate that is smaller than the reference category. For example, in Table 3, Model 1, those with a tertiary degree are approximately 1.6 times less likely (i.e. $1 \div 0.62=1.61$ ) than the non-tertiary educated to claim convict descent as opposed to not claiming.

21 After an initial examination and in the interests of parsimony, we dropped the occupational variables from our regression models, as the impact of occupation was rendered non-significant $(p>.05)$ by tertiary education and income.

22 Using the question 'How interested are you personally in learning about your family tree or your family's history?' (responses: very interested; somewhat interested; not at all interested). We 
combined the 'very' and 'somewhat' interested categories and contrasted these with the 'not at all interested' group. The mean age of those claiming to be interested in searching their family tree was 46.6, compared to 49.6 for those not interested, a difference significant at $p<.01$.

23 Lambert (2002: 114) interviewed 46 members of two Australian convict-descendant societies in 1999 , where the 'mean age of respondents was 63 years and 70 percent were women'.

24 That is, analyses of national survey data contrasted with Lambert's (2002) qualitative interviews of members of genealogical societies.

25 The question was: 'And how much interest would you say you took in the referendum campaign overall? (A good deal, some; not much; none)'. In this instance we combined the categories 'a good deal' and 'some', and contrasted these with the 'not much' and 'none' responses.

26 'Indigenous children have been forcibly separated from their families and communities since the very first days of the European occupation of Australia' (Human Rights and Equal Opportunity Commission 1997). Since the Commonwealth-State Native Welfare Conference in 1937, 'States began adopting policies designed to "assimilate" Indigenous people of mixed descent. Whereas "merging" was essentially a passive process of pushing Indigenous people into the non-Indigenous community and denying them assistance, assimilation was a highly intensive process necessitating constant surveillance of people's lives, judged according to non-Indigenous standards' (Human Rights and Equal Opportunity Commission 1997). Such children are now referred to as the 'stolen generations'.

27 'In the closing years of the twentieth century the Aboriginal presence became inescapable. The census revealed a dramatic increase of numbers, from 156,000 in 1976 to 352,000 by the late 1990s' (Macintyre 1999: 261).

28 The claim to Aboriginal identity has been redefined to the point that it is now a contested status. Tasmania, where the original inhabitants were 'long thought to have disappeared, now found that it had 14,000 of them' (Macintyre 1999: 261). This has resulted in disputes both within the indigenous community (Mansell 2001: 5), and in the wider community, as individuals whose indigenous status has been challenged have appealed to the Supreme Court for inclusion on the Aboriginal Land Council Electoral Roll (Whinnett 2001: 7).

29 Hout and Goldstein (1994: 70) point out that intermarriage 'creates the opportunity for preferential identification, the process whereby one or several ethnic origins are selectively forgotten and others are selectively remembered', and in addition 'the possibility of multiple responses to questions about ethnicity'. That is, children of 'mixed' ethic backgrounds were able to claim more than one ethnicity in the survey data analysed by Hout and Goldstein.

30 Using Logistic regression analyses, we modelled those who said they were, or may be, descended from convicts, as opposed to not being descendants, with voting in the House of Representatives in 1998 (i.e. Labor versus Liberal party with other parties excluded) as the dependent variable. Those claiming convict ancestors were significantly more likely to have voted Labor than for the Coalition parties (O.R. 1.3; $p=.0352$ ), although when we controlled for selfassessed class, this relationship was rendered non-significant at the 95 per cent level (O.R. 1.2; $p=.1922)$.

31 For example, Pakulski and Tranter found that 'Ethno-nationalists tend to blame immigrants more frequently than those with a civic identity for taking jobs away from locals and for increasing crime rates. They would also like to restrict the right of political refugees to stay in Australia' (2000b: 217).

32 We are not suggesting that those making such 'white' ethnic identity claims have racist motivations.

33 Again we stress that these city findings are not due to the large migrant communities in larger cities, as they remain when we control for parental country of birth.

34 The term 'convict chic' seems to have been coined, or at least became popular, around the time of the bi-centennial celebrations of Captain Cook's landing on Australian soil in 1988 (see Sayle 1988; Bennett 1988). It refers to the popularity of all things convict-related during this period, such as genealogical searches for convict ancestors and the popularity of convict-related tourist attractions. 


\section{References}

Australian Bureau of Statistics. 2002. Australian Social Trends 2000: Population National Summary Tables. http: //www.abs.gov.au/Ausstats/abs\%40.nsf/94713ad445ff1425ca25682000192af 2/3f9dac27a892d5d6ca256bcd008272e9! OpenDocument

Agresti, A. 1996. An Introduction to Categorical Data Analysis. New York: Wiley.

Anderson, B. 1991. Imagined Communities, revised edition. London: Verso.

Bennett, T. 1988. 'Convict chic', Australian Left Review 106: 40-1.

Bennett, T., M. Emmison and J. Frow. 1999. Accounting for Tastes: Australian Everyday Cultures. Cambridge: Cambridge University Press.

Betts, K. 1999. The Great Divide: Immigration Politics in Australia. Sydney: Duffy and Snellgrove.

Blainey, G. 1966. The Tyranny of Distance: How Distance Shaped Australia's History. Melbourne: Sun Books.

Bourdieu, P. 1984. Distinction: A Social Critique of the Judgment of Taste. London: Routledge \& Kegan Paul.

Bourdieu, P. 1991. Language and Symbolic Power. Cambridge: Polity Press.

Bradley, H. 1996. Changing Patterns of Inequality. Cambridge, MA: Polity Press.

Calhoun, C. 1994. Social Theory and the Politics of Identity. Oxford: Blackwell.

Clark, M. 1986. A Short History of Australia. Ringwood: Penguin Books.

de Vaus, D. 2002. Surveys in Social Research, fifth edition. Sydney: Allen and Unwin.

Erickson, B. 1996. 'Culture, class and connections', American Journal of Sociology 102(1): 217-51.

Fletcher, B. 1992. 'Australia's convict origins: myth and history', History Today 42(October): 39-43.

Gans, H. 1974. Popular Culture and High Culture: An Analysis and Evaluation of Taste. New York: Basic Books.

Gow, D., C. Bean and I. McAllister. 2000. Australian Constitutional Referendum Study, 1999: Users Guide for Machine Readable Data File [SSDA 1018]. Canberra: Social Science Data Archive, Australian National University.

Hall, S. 1990. 'Cultural identity and diaspora' in J. Rutherford (ed.), Identity. London: Lawrence and Wishart, 222-37.

Hay, P. 2000. The Strange and Verdant Politics of a Strange and Verdant Island. Institute of Island Studies, Charlottetown, Canada: University of Prince Edward Island.

Hewitt, J. 1989. Dilemmas of the American Self. Philadelphia: Temple University Press.

Horne, D. 1964. The Lucky Country. Ringwood: Penguin.

Hout, M. and J. Goldstein. 1994. 'How 4.5 million Irish immigrants became 40 million Irish Americans: demographic and subjective aspects of the ethnic composition of white Americans', American Sociological Review 59: 64-82.

Hughes, R. 1987. The Fatal Shore. London: Knopf.

Human Rights and Equal Opportunity Commission. 1997. Report of the National Inquiry into the Separation of Aboriginal and Torres Strait Islander Children from Their Families. Sydney: Commonwealth of Australia. http://www.hreoc.gov.au/social_justice/stolen_children/index.html

Jones, F.L. 1997. 'Ethnic diversity and national identity', Australian and New Zealand Journal of Sociology 33: 285-305.

Jones, F. and P. Smith. 2001. 'Diversity and commonality in national identities: an exploratory analysis of cross-national patterns', Journal of Sociology 37(1): 45-63.

Lambert, R. 2002. 'Reclaiming the ancestral past: narrative, rhetoric, and the "convict stain"”, Journal of Sociology 38(2): 111-27.

Long, J. S. 1997. Regression Models for Categorical and Limited Dependent Variables. Thousand Oaks: Sage.

Macintyre, S. 1999. A Concise History of Australia. Melbourne: Cambridge University Press.

McQueen, H. 1986. A New Britannia: An Argument Concerning the Social Origins of Australian Radicalism and Nationalism. Ringwood: Penguin.

Mansell, M. 2001. 'Mansell calls for election clean-up', The Mercury 29 January 2001. 
Morgan, S. 1987. My Place. Fremantle: Fremantle Arts Centre Press.

Nagel, J. 1995. 'American Indian ethnic renewal: politics and the resurgence of identity', American Sociological Review 60: 947-65.

Pakulski, J. and B. Tranter. 2000a. 'Civic, national and denizen identity in Australia', Australian Journal of Social Issues 5(1): 34-50.

Pakulski, J. and B. Tranter. 2000b. 'Civic, national and denizen identity in Australia', Journal of Sociology 36(2): 205-22.

Pakulski, J. and B. Tranter. 2002. 'Collective identities in a comparative perspective', Mimeo, School of Sociology, University of Tasmania.

Phillips, T. 1996. 'Symbolic boundaries and national identity in Australia', British Journal of Sociology 47(1): 113-34.

Phillips, T. 2000. 'What is "Australian"? Knowledge and attitudes among a galley of contemporary Australians', Australian Journal of Political Science 35(2): 203-24.

Pusey, M. 1988. 'State and polity' in J. Najman and J. Western (eds.), A Sociology of Australian Society. South Melbourne: Macmillan.

Robson, L. 1965. The Convict Settlers of Australia: An Enquiry into the Origin and Character of the Convicts Transported to New South Wales and Van Diemen's Land, 1787-1852. Carlton: Melbourne University Press.

Sayle, M. 1988. 'Where convicts are chic and the past looks good', Far Eastern Economic Review 139(4): 44-50.

Siggner, A. 1993. 'Socio-demographic conditions or registered Indians' in R. Silverman and M. Nielson (eds.), Aboriginal Peoples and Canadian Criminal Justice. Toronto: Butterworths.

Smith, A. 1991. National Identity. London: Penguin.

Smith, A. 1996. 'LSE Centennial Lecture: the resurgence of nationalism? Myth and memory in the renewal of nations', British Journal of Sociology 47(4): 575-98.

Smith, A. 1999. Myths and Memories of the Nation. New York: Oxford University Press.

Snipp, C. 1992. 'Sociological perspectives on American Indians', Annual Review of Sociology 18: 351-71.

Turner, B. 1988. Status. Milton Keynes: Open University Press.

Tyler, W. 1999. 'Aboriginal criminology and the postmodern condition', Australian and New Zealand Journal of Criminology 32(2): 209-21.

Ward, R. 1958. The Australian Legend. Melbourne: Oxford University Press.

Warhurst, J. 1993. 'Nationalism and republicanism in Australia: the evolution of institutions, citizenship and symbols', Australian Journal of Political Science 28(special issue): 121-35.

Weeks, J. 1990. 'The value of difference' in Rutherford J. (ed.), Identity. London: Lawrence and Wishart, 88-100.

Whinnett, E. 2001. 'Appeal on Aboriginality claim denied', The Mercury. 26 August: 7. 